This is an electronic reprint of the original article. This reprint may differ from the original in pagination and typographic detail.

Please cite the original version: K. Kuparinen (2018) A Living Landscape - Using the Multisensory Space in Second Language Learning, ICERI2018 Proceedings, pp. 7613-7616.

doi: $10.21125 /$ iceri.2018.0364 


\title{
A LIVING LANDSCAPE - USING THE MULTISENSORY SPACE IN SECOND LANGUAGE LEARNING
}

\author{
K. Kuparinen \\ Laurea University of Applied Sciences (FINLAND)
}

\begin{abstract}
This paper discusses a work in progress in a project call ELO - Building Skills and Communities Together (2017 - 2019). The project is funded by ESF (European Social Fund) and it focuses on immigrants outside the labor force. The aim of ELO is to provide diverse tools to promote non-formal training of L2 (second language) as well as information about the culture and society. A prominent feature of the project is co-creation, it is the skills needed in everyday life in Finland are to be developed together by the project stakeholders.

ELO utilizes Multisensory Space Method which is an experiental learning environment that has been developed for a decade by Laurea University of Applied Sciences in Finland. The core of the method is an easily modified space where photographs, images, sounds and items create diverse learning environments. It has been used for a variety of purposes, for example multicultural encounters, promoting health and wellbeing as well as language teaching.

By entering the space one is able to step into a new landscape and leave all other behind: it's an alluring place for language learning in a relaxed and motivating way. However, the current work of development differs somewhat from previous experiences of using the method. This paper first introduces the theoretical framework of the work at hand. The development of the learning environment is based on sociocultural insight of language learning and on action-based pedagogy. The concept of affordance is introduced. The procedure of mapping the target groups' needs and means on inclusion in planning the training is then being described. Finally, the paper illustrates the role of the volunteer facilitators of L2 training.
\end{abstract}

Keywords: Non-formal language learning, second language, learning environment, affordance.

\section{INTRODUCTION}

Imagine yourself strolling in parallel but different landscapes: from a misty northern Europe suburb full of traffic you only need to take a couple of steps to move to a marketplace bursting with sunshine, sounds of people bargaining of spices, smell of chai in the air - or a cottage in the woods a hundred years ago with a pack of wolves howling around a corner. This is what you can experience when you enter the multisensory space. Multisensory Space Method is an experiental learning environment that has been developed for a decade by Laurea University of Applied Sciences in the capital city area of Finland [1]. The core of the method is an easily modified space where photographs, images, sounds and items create diverse learning environments. It has been used for a variety of purposes, for example for multicultural encounters, for promoting health and wellbeing as well as for language teaching. [2, 3]

In this paper of work-in-progress The Multisensory Space Method is the vehicle of promoting the aims of a project called ELO - Building Skills and Communities Together (2017-2019) funded by European Social Fund (ESF). The project focuses on immigrants outside the labor force and it aims at their social inclusion by twofold means: one of the objectives is to induce the immigrants to construct spaces meaningful to them. The purpose of these spaces is both to convey topics that they find important and to encounter and interact with others while planning, collating the items and finally presenting the space. The other main objective is to create diverse practices to enhance non-formal learning of second language (L2) alongside cultural and societal information. This paper focuses on the latter.

A prominent feature of the project is co-creation, it is the skills needed in everyday life in Finland are to be developed together by the project stakeholders with the support of the project's experts in Laurea UAS, Espoo City libraries and Finnish Red Cross. 
The share of immigrant population in Finland at the end of year 2017 was around $7 \%$ [4]. In comparison to some European Countries this is a modest number and this is reflected e.g. in the services provided for the immigrants, among them the integration training of Finnish or Swedish. The Integration Act (1386/2010) sets the guidelines to initial assessment and language training [5] but the implementations vary according to immigrant's status, local resources and the flow of people looking for asylum. This is why there are immigrants who are excluded from language training or who face a lengthy period of queuing for language studies.

The ELO project seeks to tackle the detachment of these people by organizing diverse sessions of encounters and non-formal language learning in the multisensory space at Laurea premises. The method is also promoted to groups outside the UAS with mobile versions of it to be used in public and open places, such as libraries.

\section{SOCIOCULTURAL INSIGHT OF LANGUAGE LEARNING AND ACTION- BASED APPROACH AS THE FRAMEWORK}

The use of the Multisensory Space Method differs from the previous experiences in three prominent perspectives: the format of the training is different than before, the role of the facilitators differ from their earlier experiences and the communication skills of the participants might need more consideration than in many other cases.

A major variable from the point view of an institution is that the language training in this learning environment is not conducted according to a curriculum nor do participants get any credits of their outcomes. This is to say that the method is used in non-formal framework. [6] Non-formality is a necessity regarding the various positions of the immigrant participants and their possibilities of accessing and committing to the training. Non-formality, however, does not mean that the training sessions wouldn't have any structure or goals. Different from formal training the goals might vary within participants.

To enhance more than incidental learning in this framework, the actions are based in sociocognitive insight of language learning [7] and in action-based pedagogy [8] to ensure participants' possibilities of agency. From the sociocultural viewpoint language learning is understood more pervasively than in narrow traditional thinking; learning is seen as part of social co-operation that enables social inclusion. This in turn opens up possibilities of moving on the economical scale and of having an influence on one's surroundings. Learning is a transaction of different agents, interaction, the surroundings and other artefacts rather than textbook-based policies that often focus on looking for one correct reply. The language is linked to actions and the environment can even guide the actions. The teacher isn't the sole guide of the situation but the learners can learn from each other or from someone that already knows something more - all of this through dialogue. [7]

The sociocultural perspective of learning highlights the agency of the learner [8]. The agency in L2 learning is constructed by meaningful opportunities of learning and it can be reached by action-based pedagogy. In order to create meaning in learning we need to give a voice to the individual perspective of the learners, we need to see their dreams, worries and beliefs - their position in the past, present and future. [8] The purpose of this is to prepare the learner to situations outside the classroom. The important outcomes of learning are the learners' possibilities of transferring the skills practiced in everyday encounters.

To reach this, the action-based approach is focused on the process of learning. The process starts out with activities, needs and emergent purposes of the learner. Through the action we can facilitate the learner to perceive linguistic items to be explored and understood. This placed in the multisensory space we look at the landscape together but each of us make our own perceptions that are then elaborated in a dialogue. This is how the learners' surroundings are transformed as their affordances that can help them to cope in their everyday needs. This way the process supports the autonomy of the learner and provides tools for rebuilding one's identity in a new environment and changed circumstances. [8]

\section{FINDING OUT ABOUT THE PARTICIPANTS' NEEDS}

As described above, the emergent needs of the participants are the starting point of meaningful learning. In order to find out about these, ELO started out with field work among groups of immigrants studying Finnish in different surroundings. The groups were coordinated by volunteers. The target of 
this exploration was having the immigrants to take pictures of their environment - pictures of important places in terms of using Finnish. There were three possible topics of the photos: places where you can speak Finnish, places were you need to speak Finnish and places where you would like to speak Finnish.

The field work was implemented by UAS students of social services and there were some obstacles in collating the photos. It was hard to get in touch with the groups and even harder to convey the purpose of this collaboration to the immigrant learners. Nevertheless, the students managed to work with some immigrants in taking the photos and the project team got pictures to start with. Landscapes with bus-stops, hallways of health care centers and sports venues - scenes of everyday life even quite uninspiring for L1 speakers. This is just why it was important to include the participants' needs and visions in order to develop something meaningful to work with in the learning environment.

If possible in regard to a common language, the immigrants involved in taking the photos had the opportunity of explaining the meaning of a certain place to them. The bus-stop, for example, represented the effort of being able to move around without a need to depend on others. The photo of healthcare surrounding was due to insecurities in terms of coping with the system and the language. The sports venues, among others, reflected the need of social encounters. These notions reflect van Leer's idea that meaning is constructed by striving to autonomy in individual level and the feeling of belonging in social level [8].

\section{VOLUNTEERS SCAFFOLDING THE LEARNER}

Driven by these examples as well as other encounters with the project's target group the project team decided to develop the use of multisensory space within L2 learning focusing on three themes: using public transport, health and wellbeing and work in Finland. The themes are elaborated considering the societal and cultural aspects. The tools created around the topics consist on one hand of pictures, sounds and other artefacts related to the theme. On the other hand there are instructions to different kind of activities to the facilitator of the group to choose from. The purpose of the activities is diverse; some aim at empowering group dynamics and building confidence, some are meant to set the scene of the topic and some are to enhance creativity. None of these, however, are meant as the sole content of a session. They are to spark the group into a meaningful dialogue around the theme.

The multisensory space is a flexible learning environment in terms of language skills and its use can be easily modified according to the language levels of people attending a session. For a beginner the scenery is source of vocabulary and the context of simple interaction, for the more advanced it's an incentive of discussion and the scene of more complex interaction and narratives. The space is a safe place for repetition and testing new elements.

The group of learners may consist of people of various backgrounds and different level of previous knowledge. This can be seen both as a challenge and as an asset to the volunteer facilitating the activities of a group. The immigrants taking part in the activities may have little previous knowledge of Finnish, it's even possible that they have hardly any common language with the others. However, the pictures, sounds and artefacts with as well as information technology and the group as a whole can support both the participant and the facilitator in these situations. The role of the volunteer facilitating the session is to observe the participant in order to be able to offer the kind of support that's needed at the moment. This kind of interactive support in problem solving is called scaffolding [9] - the idea is to offer support that can be gradually decreased and finally dropped as the learner manages to cope without the scaffolds.

In an ideal case the volunteer guiding a group of language learners might have ample opportunities of supporting the learner. In reality the premises and the props of the volunteers can be very diverse and limited. This is why the ELO team together with volunteers is now piloting a light, mobile version of landscaping - there are suitcases containing thematic artefacts and props and instructions to help out with the activities. It is up to the volunteers' will and motivation to use the tools, so it's essential to make them easily applicable to the future users.

\section{CONCLUSIONS AND WAY FORWARD}

Immigration is one of the most significant phenomenon of our time and the future. It poses many challenges to the ideal of Lifelong Learning [10]. As globalization proceeds, we'll need various ways of language training that can be implemented also by voluntary language guides and we'll need multiple 
tools and pathways of inclusion. Using non-formal training to complement existing educational structures can make learning accessible to more people and even cut down some public costs [11].

Regarding this there are many positive aspects in using the Multisensory Space Method in L2 training. The method focuses on the individual participant rather than in teaching. The purpose of the space is to foster the learning cycle that starts with action, proceeds to perception and aims at understanding and applying. This process in turn supports the learner in making surroundings into affordances. This reflects well the modern, holistic understanding of language learning and it serves excellently the training provided for those who are excluded from formal measures. One might even say that in this development process virtues have been made of necessities.

The ELO team is now working on a series of photographs dealing with vocational training, as the immigrants involved in different sessions have found this to be an interesting field of exploration. In Finnish ELO means both 'life' and 'harvest'. The project so far has seen many landscapes full of life and the team now looks forward to harvesting and presenting both the method descriptions and the tools created on the project website in early 2019.

\section{REFERENCES}

[1] M. Räty, S. Sivonen, J. Saarela \& H. Laurikainen. Aistien-menetelmä. Laurea Julkaisut 20. Laurea-ammattikorkeakoulu, 2013.

[2] The Multisensory Space Method. Retrieved on 17.9.2018 from https://www.aistienmenetelma.net/files/7414/3400/9829/Multisensory_Space_Method_Laurea_II .pdf.

[3] S. Myréen. Evaluating the Role of Multisensory Elements in Foreign Language Acquisition. International Journal of Social, Behavioral, Educational, Economic, Business and Industrial Engineering, 11(2), p. 375-378, World Academy of Science, Engineering and Technology, 2017.

[4] Statistics Finland's PX-Web databases. Numbers and shares of persons with immigrant background by area 1990-2017. Retrieved on 17.9.2018 from http://pxnet2.stat.fi/PXWeb/ pxweb/en/Maahanmuuttajat_ja_kotoutuminen/Maahanmuuttajat_ja_kotoutuminen_Maahanmu uttajat_ja_kotoutuminen/007_ulkom_osuudet.px/?rxid=a95785ab-af42-418d-87f4994b394aa90a

[5] The Integration Act 1386/2010.

[6] H. Colley, P. Hodkinson \& J. Malcolm. Non-formal learning: mapping the conceptual terrain. A Consultation Report. Leeds: University of Leeds Lifelong Learning Institute.

[7] H. Dufva. Kognitio, kieli ja oppiminen: hajautettu näkökulma. [Distributed language and cognition.] in T. Keisanen, E. Kärkkäinen, M. Rauniomaa, P. Siitonen \& M. Siromaa (eds.) AFinLA-e soveltavan kielitieteen tutkimuksia 2013/ n:o 5. 57-73, 2013.

[8] L. van Leer. Action-based Teaching, Autonomy and Identity. Innovation in Language Learning and Teaching. Volume 1, 46-65, 2007.

[9] D. Wood, J. Bruner \& G. Ross: The Role of Tutoring in Problem Solving. Journal of Child Psychology \& Psychiatry. Vol. 17. Pergamon Press. 89-100, 1976.

[10] S. Roche. Learning for life, for work, and for its own sake: the value (and values) of Lifelong Learning. UNESCO Institute for Lifelong Learning. Volume 63, Issue 5, 623-629, 2017.

[11] P. Werquin. Recognition of non-formal and informal learning in OECd countries: A very good idea in jeopardy? Lifelong learning in Europe. 142-149, 2008. 